\title{
Evolving Access to Educational Materials
}

\author{
Michael Paskevicius \\ Faculty of Education \\ University of Victoria
}

\section{Correspondence:}

Michael Paskevicius

University of Victoria

Email: mpaskevi [at] uvic.ca

\begin{abstract}
The purpose of this paper is to interrogate the ways in which the selection of educational materials results in implications that impact access to these materials. This is necessary considering the evolving nature of educational materials offered by traditional publishers, and the increase in the availability of online learning materials, among those, open educational resources. I begin by reviewing the existing literature on emerging problems and barriers to learners' access to educational materials including textbooks, online learning resources, and open educational resources. The findings from the literature review confirm that learners are now engaging with an increasingly complex ecosystem of educational materials, both print and digital, in a multitude of differing forms and formats, with various terms of use and durations of sustained access. Educators have a variety of choices to make when considering the educational materials to be used in their courses, and while fitness for purpose still dominates as the most important selection criterion, ease and persistence of access are becoming important considerations. A model which encapsulates the findings considering the variety of educational materials is presented alongside a discussion about the specific considerations for each.
\end{abstract}

Keywords: access, educational materials, textbooks, inclusive access subscriptions, open educational resources 


\section{Introduction}

There is a growing global demand for education and as a result, a greater need to access educational materials. Learning activities, lesson plans, textbooks, presentations, simulations, and other educational materials are typically used in learning activities to help mediate learner understanding of concepts and provide resources for learning. In the context of higher education, educators are usually responsible for selecting educational materials and learners are responsible for gaining access to them. Some have argued that this contradiction is highly problematic because those responsible for selecting resources are not required to pay the price to obtain them, with the implication that considerations around how learners acquire materials and at what cost are not front of mind for the decision maker (Richardson, 2015). In developing countries the situation is compounded, as educators and learners remain heavily dependent on imported textbooks and reference books, and in many cases these resources are exceptionally expensive and may lack local context and cultural nuances to ensure they are relevant for learners (Barton et al., 2002; Goodier, 2017; Hodgkinson-Williams et al., 2017; Kanwar et al., 2010).

\section{Commercial Education Materials}

Traditionally, educational publishers have offered physical copies of educational materials, usually at a cost, to schools and learners. More recently, publishers are providing educational materials offered in digital formats, as either supplements to, or replacements for, printed materials. In many cases, learners are required to subscribe to these online services by registering an account with the provider. The ways in which these resources are made available to learners should be problematized because they may have potential limitations on the duration learner are able to use them, may require specific methods and tools in order to access them, and prompt considerations around ownership and the ethical use of learner data obtained through their usage. These types of resources may include digital versions of textbooks, ancillary or supplementary materials, applications, games, and learning environments that may be intended to complement traditional materials. These materials may be included with the textbook or offered online at a cost, through user registration, or as openly available resources for users. Often, access to these resources requires that a learner has a computer or mobile device or the ability to print online resources for use as needed. Worth noting is that many of these online resources are not suitable for print (for example, online interactive software, games, videos, etc.). Some of these online resources also include technical restrictions known as digital rights management (DRM). These restrictions, commonly known as digital locks, technologically limit the user from freely using, printing, copying, marking up, and highlighting the resource and often require that it be accessed exclusively while the user is connected to the internet (McGreal, 2017).

Publishers have also started changing their business models, with the introduction of "inclusive access" subscriptions. These models involve educational institutions partnering with publishers to make online educational materials available to learners, rather than having each student individually purchase their educational materials. The cost of these educational materials is then bundled with the course fees and applied when learners enroll for a course (McKenzie, 2017). Publishers claim they can offer these resources at significant discounts by making them available in digital formats to many learners (Pearson, 2017; VitalSource, n.d.). The use of these subscriptions appears to be gaining popularity, at least within the United States. In their 2019 report Seaman and Seaman reported that $37 \%$ of educators required learners to use an 
online homework system, and 7\% described the use of an inclusive access subscription to use learning materials. While these types of resources are increasingly being adopted by educators, they still come at a cost to learners with both monetary and accessibility considerations. Using the inclusive access model, learners may have fewer options around retaining the material indefinitely, using a library copy, or selling their used copy of the resource to recover some of the initial cost. Essentially, learners pay a fee to use their educational materials for the duration of a course when using the inclusive access model, rather than owning the material, without the ability to sell it to recover cost or retain it for future reference (McKenzie, 2017). Hendricks (2019) noted that these types of services are increasingly being prescribed as a required part of a learning experience, and as a result, learners are essentially mandated to use the service with the conditions defined by the publisher. While prescribing traditional textbooks creates some choice for learners in that they can purchase an old copy, use a library copy, or buy a digital version, inclusive access materials may only be made available through the publisher's website and require that each learner register an account to use them.

\section{Online and Open Educational Materials}

An alternative to sourcing materials from publishers is to use educational resources that are freely available online. Increasingly, educators and organisations are sharing the educational materials they create online which can be accessed by educators and learners using the internet. Some, but not all, of these resources are shared using open licences that allow their reuse, adaptation, and re-sharing by others. The distinction between "online" and "open" resources is important and has implications for those accessing educational materials online. When resources are just placed online without an explicit statement around copyright, by default the right to copy or adapt rests with the author. While they are free to access, without a statement explicitly enabling reuse or modification these materials have more ambiguous terms for their use, adaptation, and redistribution. Open licensing provides a way to indicate that a resource is both free and includes permissions, such as the ability to retain, reuse, remix, revise, and redistribute the material (Wiley, 2014). Open licensing can be used to make these permissions explicit but are not applied uniformly across the internet.

Many educators and organizations are sharing digital educational materials as open educational resources (OER) with open licensing made explicit (Merkley, 2015). Educators are increasingly recognizing OER as a potential source for finding and adapting educational materials to meet their pedagogical needs (Jhangiani et al., 2016; Seaman \& Seaman, 2019). Many OER provide added flexibility in how they can be used, adapted, and retained by both educators and learners.

\section{Forms of Educational Materials: A Model for Discussion}

Educators now have a variety of choices to make when considering the educational materials to be used in their courses. While fitness for purpose still dominates as the most important selection criterion, ease and persistence of access are becoming important considerations that need to be recognized (Horsley, 2012; Jung et al., 2016; Reichenberg, 2016). Additionally, what both educators and learners can do with their learning resources is an important consideration. Educators may want to modify or adapt resources for the development of online courses, learning activities, or assessment activities. Learners may desire to search, copy, annotate, edit, or combine materials with others to create new knowledge artefacts (Paskevicius, 2019). Furthermore, learners may value retaining their copy of the learning material for future reference. 
Figure 1 provides an overview of the variety of forms of educational materials discussed above, and some of the specific considerations for each; the information is adapted from Czerniewicz's (2018) report on the unbundling of higher education, which includes learning resources as part of the discussion.
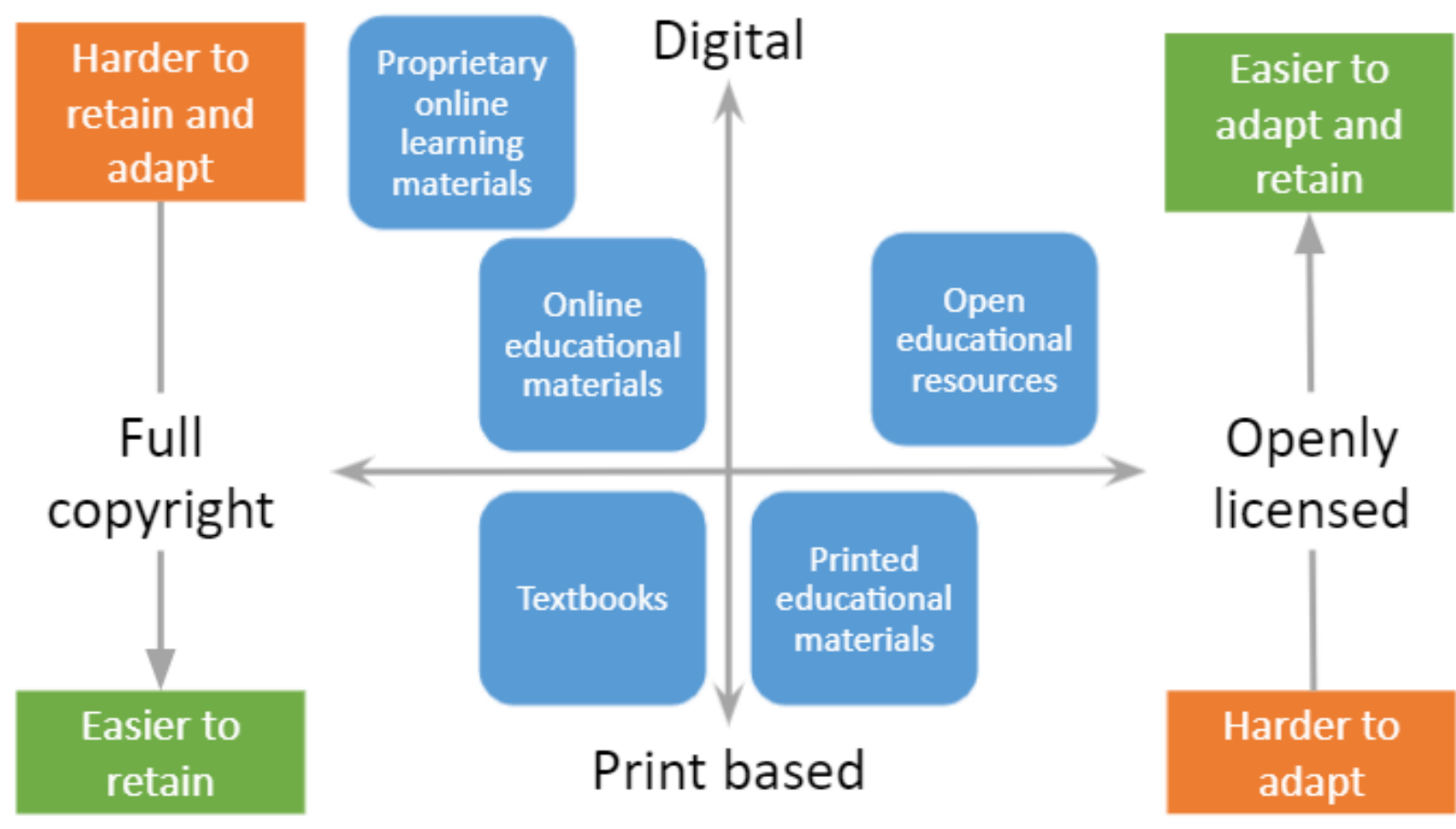

Figure 1. Forms of educational materials (adapted from Czerniewicz, 2018, licensed under a Creative Commons Attribution 4.0 International Licence)

It is important to consider how selecting a traditional copyright or openly licensed resource impacts our learners. This can be considered in terms of both format (print versus digital) and copyright (full/closed versus an open license). As well, the difference between a copyrighted and an openly licensed print resource is different than for a digital resource. Printed materials that fall under traditional copyright categories are easier to retain than many copyrighted digital materials, which now include leasing terms, DRM, and other restrictions. On the other hand, openly licensed materials, both printed and digital, are often easier for learners to retain. Furthermore, when considering openly licensed materials, those offered in digital formats are also easier to adapt, when made available in editable formats. This means that learners can annotate, highlight, and mark up resources to support their learning, and educators can customise and adapt them to meet the goals of their course.

\section{Promise and Perils of OER}

One of the goals of OER was to provide resources that were free of encumbrances to be used, adapted, and re-shared by educators and learners. Hodgkinson-Williams and Gray (2009) proposed that OER can ideally include four key attributes of openness: (a) technical openness refers to the accessibility of the resource itself and the ability to easily adapt or remix the educational material (this may include file formats and interoperability standards); (b) legal 
openness indicates to the open license applied to the materials, enabling legal reuse and modification; (c) social openness includes the willingness of the author of the material to make their work available and relevant beyond traditional contexts (for example, their own classroom or university); and (d) financial openness, which means the resource comes with no additional costs to use or adapt (Hodgkinson-Williams \& Gray, 2009). Many OER contain some of these elements but not necessarily all, which may result in challenges for those looking to reuse these resources. For example, an OER that an educator wants to adapt that has been shared as a PDF file, making it harder to remix and modify without an editable source file (i.e., technical openness). Similarly, videos shared as OER and distributed using a video streaming platform such as YouTube cannot be easily downloaded for adaptation. As well, an OER shared with a license that does not allow derivative works may prohibit an educator adapting it contextually to make it more relevant for their learners (i.e., legal openness). Lastly, consider an OER that is shared but requires each user to create an account with a web service in order to use, download, or adapt. This final example bridges on both technical and financial openness, because creating an account on a website may result in an exchange of data that could have financial implications (for example unsolicited email, upselling, etc.). Hodgkinson-Williams and Gray's (2009) model of technical, legal, social, and financial openness offers an important lens for thinking about OER, and provides significant guidance to those wanting to share their work in the most accessible way.

\section{Conclusion}

The purpose of this paper was to examine the literature around educational materials and present a model which seeks to provoke considerations around the implications of resource provision today. Clearly, our learners are working in a complex ecosystem of learning resources, some of which are prescribed by their teachers and some of which they may independently seek out to supplement and enhance their learning. Thoughtful attention should be given when considering the accessibility of the learning materials educators prescribe for two reasons. First, changes to the commercial publishing business models has implications for learners' sustained use of resources, and second, it should also take into account the data our learners are required to provide when registering and through their ongoing use of these services. Considering the growth of available OER and increasing adoption across higher education, learners should be made aware of what is possible with openly licensed material. As well, educators may consider the accessibility of the resources they create and select using the lens of technical, legal, social, and financial openness thoughtfully provided by HodgkinsonWilliams and Gray (2009). This model provides a useful lens to guide the creation of OER which are, in most cases, intended to be reused and adapted without encumbrances to the user.

\section{Open Researcher and Contributor Identifier (ORCID)}

Michael Paskevicius (i) https://orcid.org/0000-0001-7391-0783

\section{Ethics Statement}

An ethics review was not applicable.

\section{Conflict of Interest}

The author does not declare any conflict of interest.

Open/Technology in Education, Society, and Scholarship Association Conference Proceedings: 2021, Vol. 1(1) 1-7 


\section{References}

Barton, J., Alexander, D., Correa, C., Mashelkar, R., Samuels, G., \& Thomas, S. (2002). Integrating intellectual property rights and development policy Commission on Intellectual Property Rights. http://www.iprcommission.org/papers/text/final report/reporthtmfinal.htm

Czerniewicz, L. (2018, October 29). Unbundling and rebundling higher education in an age of inequality. EDUCAUSE Review. https://er.educause.edu/articles/2018/10/unbundlingand-rebundling-higher-education-in-an-age-of-inequality

Goodier, S. (2017). Tracking the money for open educational resources in South African basic education: What we don't know. The International Review of Research in Open and Distributed Learning, 18(4). https://doi.org/10/gf7gv2

Hendricks, C. (2019, May 24). UBC Senate endorses principles for digital learning materials used for assessment. Open UBC. https://open.ubc.ca/ubc-senate-endorses-principlesfor-digital-learning-materials-used-for-assessment/

Hodgkinson-Williams, C., Arinto, P., Cartmill, T., \& King, T. (2017). Factors influencing open educational practices and OER in the Global South: Meta-synthesis of the ROER4D project. In C. Hodgkinson-Williams \& P. Arinto (Eds.), Adoption and Impact of OER in the Global South (pp. 27-47). African Minds, International Development Research Centre \& Research on Open Educational Resources for Development.

Hodgkinson-Williams, C., \& Gray, E. (2009). Degrees of openness: The emergence of open educational resources at the University of Cape Town. International Journal of Education and Development Using ICT, 5(5), 101-116.

https://open.uct.ac.za/bitstream/handle/11427/8860/CHED article OERemergence Hod gkinsonWilliams 2009.pdf? sequence $=1$

Horsley, M. (2012). Investing in classroom teaching and learning resources: Access and equity in providing classroom teaching and learning materials in Australian schools [Report]. CQUniversity. https://hdl.handle.net/10018/927236

Jhangiani, R., Pitt, R., Hendricks, C., Key, J., \& Lalonde, C. (2016). Exploring faculty use of open educational resources at British Columbia post-secondary institutions. https://open.bccampus.ca/files/2016/04/BCFacultyUseOfOER_final.pdf

Jung, I., Sasaki, T., \& Latchem, C. (2016). A framework for assessing fitness for purpose in open educational resources. International Journal of Educational Technology in Higher Education, 13(1). https://doi.org/10/gf4zt3

Kanwar, A., Kodhandaraman, B., \& Umar, A. (2010). Toward sustainable open education resources: A perspective From the Global South. American Journal of Distance Education, 24(2), 65-80. https://doi.org/10/d3x8c8

McGreal, R. (2017). Special report on the role of open educational resources in supporting the Sustainable Development Goal 4: Quality education challenges and opportunities. The International Review of Research in Open and Distributed Learning, 18(7). https://doi.org/10.19173/irrodl.v18i7.3541

McKenzie, L. (2017, November 7). 'Inclusive access' takes off as model for college textbook sales. Inside Higher Ed. https://www.insidehighered.com/news/2017/11/07/inclusiveaccess-takes-model-college-textbook-sales

Merkley, R. (2015). State of the Commons 2017. Creative Commons.

6 Open/Technology in Education, Society, and Scholarship Association Conference Proceedings: 2021, Vol. 1(1) 1-7 


\section{https://stateof.creativecommons.org/}

Paskevicius, M. (2019). Learners' access to educational materials in select Institutions within the Commonwealth. Commonwealth of Learning (COL). http://oasis.col.org/handle/11599/3479

Pearson. (2017). Pearson PLC annual report and accounts 2017. Pearson plc. https:/www.pearson.com/content/dam/one-dot-com/one-dotcom/global/standalone/ar2017/PearsonAR17 Strategic Report.pdf

Reichenberg, M. (2016). Explaining teachers' use of textbooks. Journal of Educational Media, Memory \& Society, 8(2), 145-159. https://doi.org/10/gm2p6f

Richardson, C. (2015, January 13). The \$250 Econ 101 textbook. Wall Street Journal. https://www.wsj.com/articles/craig-richardson-the-250-econ-101-textbook-1421192341

Seaman, J. E., \& Seaman, J. (2019). Freeing the textbook: Educational resources in U.S. higher education, 2018. Babson Survey Research Group.

https://www.onlinelearningsurvey.com/reports/freeingthetextbook2018.pdf

VitalSource. (n.d.). Inclusive access. VitalSource. https://get.vitalsource.com/inclusive-access

Wiley, D. (2014, March 5). The access compromise and the 5th R. Iterating toward Openness. http://opencontent.org/blog/archives/3221 